\title{
The Theoretical and Experimental Research on the Forward Slip Coefficient in Rail Universal Rolling
}

\author{
Yong-gang DONG, ${ }^{1)}$ Wen-zhi ZHANG ${ }^{1)}$ and Jian-feng SONG ${ }^{21}$ \\ 1) College of Mechanical Engineering, Yanshan University, Qinhuangdao, China, 066004. \\ E-mail: d_peter@163.com (Y. Dong) \\ 2) College of Eletromechanical Engineering, Haerbin Institute of Technology, Haerbin, China, 150001.
}

(Received on April 21, 2008; accepted on December 10, 2008)

\begin{abstract}
In rail universal rolling, the forward slip coefficient is one of the most important parameters. For simplifying the analytic model, the vertical roll with box pass has been simplified as an equivalent flat roll firstly. Then the equation of neutral line and the area of forward slip zone on the flank of horizontal roll have been derived. Furthermore, the horizontal resultant force acting on the rolled workpiece has been obtained and the forward slip coefficient of rail universal rolling has been proposed. For verifying the theoretical model, the universal rolling process of $60 \mathrm{~kg} / \mathrm{m}$ heavy rail and $18 \mathrm{~kg} / \mathrm{m}$ light rail have been simulated by the RigidPlastic FEM software DEFORM-3D V5.0, and the universal rolling experiments of $18 \mathrm{~kg} / \mathrm{m}$ light rail has been accomplished in the Yanshan University Rolling Laboratory. Moreover, the theoretical results and numerical simulation results of forward slip coefficient are in agreement with the experimental data basically. So, this theoretical model can be applied in rail universal rolling.
\end{abstract}

KEY WORDS: rail; universal mill; neutral angle; neutral line; backward slip; forward slip; rigid-plastic FEM; simulation; experiments.

\section{Introduction}

Since 1970 s, the universal rolling method has been applied in H-beam rolling widely and the corresponding theoretical research has been carried out, ${ }^{1-8)}$ moreover, the numerical simulation by FEM has been used in universal

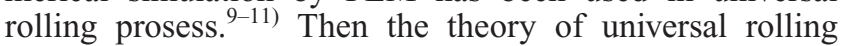
method has been developed and improved. Although the universal rolling method has been also applied in heavy rail rolling for 30 years, there are few theoretical research about the rail rolling by universal mills. At present, the application of universal rolling method becomes more and more prevalent in producing the high-precision rail, and it has been replacing conventional producing methods gradually. For the certain similarity of rail rolling and H-beam rolling, the result of theoretical research about H-beam rolling can be applied as an available reference in rail rolling.

The universal mill comprises four rolls, two horizontal drive rolls and two vertical driven rolls (Fig. 1). The horizontal roll and the vertical roll of rolling rail base is flat, but the box pass has been grooved on the vertical roll of rolling rail head.

At present, the following methods have been applied in the derivation of forward slip coefficient of universal rolling generally: (1) force equilibrium method; (2) analogical method; (3) regression method; (4) theoretical-empirical equation method. By the force equilibrium method, many influence factors have been considered in the derivation process of forward slip coefficient. So the forward slip coefficient of rail universal rolling is derived by the force equilibrium method in this paper.

\section{The Simplified Model of Vertical Roll for Rolling the Top of Rail}

In rod (or bar) rolling process, the roll surface is not flat for the groove on the roll, so previous researchers ${ }^{12-14)}$ pro- posed the concept of "mean roll radius", which has been used as equivalent radius to replaces the varying roll radius along the roll axis. In earlier work by Yong-gang Dong and Wen-zhi Zhang, ${ }^{15)}$ the concept "critical point on the contact boundary" was proposed, moreover, a new analytical model for the calculation of mean roll radius in RoundOval-Round pass sequence was represented.

In rolling the top of the rail, the roll radius is not constant along the direction of vertical roll axis. For simplifying the model of rail universal rolling, the vertical roll with box pass can be simplified as an equivalent flat roll, the radius of which is equal to the mean roll radius of box pass.

As can be seen in Fig. 2, the stress free surface of the outgoing workpiece, which does not contact with the side wall of box pass, can be predicted as an oblique plane. The angle $\theta$ of this plane varies from 0 to $\alpha$ with the change of the maximum spread $\Delta b_{t}$ in the box pass. So $\theta$ can be shown as

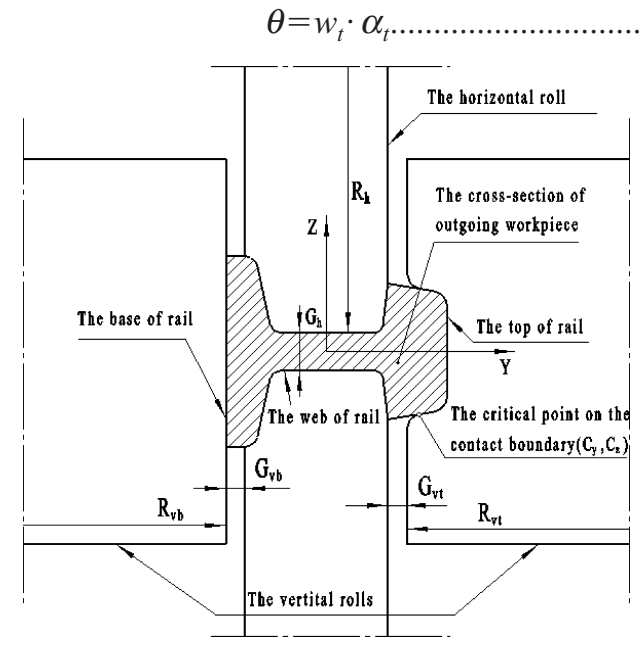

Fig. 1. Schematic plan of rail universal rolling. 


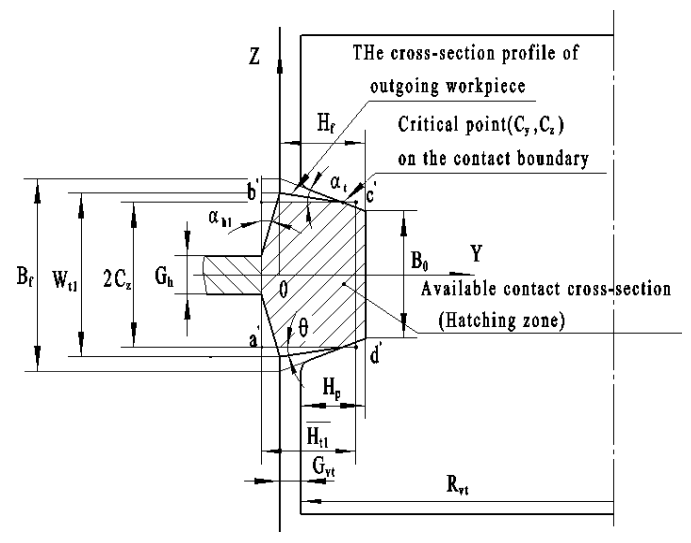

Fig. 2. Schematic plan of deformation zone.

where $\alpha_{t}$ is the angle of side wall of box pass, $w_{t}$ is a weighting function, it can be shown as

$$
\begin{gathered}
w_{t}=\frac{\Delta b_{t}}{2 H_{f} \cdot \tan \alpha_{t}} \\
\Delta b_{t}=W_{t 1}-W_{t 0} \cdots
\end{gathered}
$$

where $H_{f}$ is the height of box pass, $W_{t 0}$ is the width of incoming workpiece, $W_{t 1}$ is the width of outgoing workpiece, $B_{0}$ is the minimum width of box pass, $B_{f}$ is the maximum width of the box pass. it can be shown as

$$
\begin{gathered}
B_{f}=B_{0}+2 H_{f} \tan \alpha_{t} . \\
H_{f}=G_{v t}+H_{p} \ldots \ldots .
\end{gathered}
$$

The width of the top of rail at the exit section $W_{t 1}$ can be calculated by the Modified B. K. Smirnov equation ${ }^{16}$ )

$$
W_{t 1}=\beta_{t} \cdot W_{t 0}
$$

$$
\beta_{t}=c_{w t}\left[1+0.0714\left(\frac{1}{\eta_{t}}-1\right)^{0.862} A^{0.746} a_{0}^{0.763} \varphi^{0.160} \tan \alpha^{0.362} c_{m}\right]
$$

$$
\begin{gathered}
c_{w t}=1+\frac{\eta_{t}-\eta_{w}}{\eta_{w}} w_{f} \\
A=\frac{R_{v t}-H_{f}+G_{v t}}{H_{f}} . \\
a_{0}=\frac{H_{t 0}}{W_{t 0}} \ldots \ldots \ldots \\
\frac{1}{\eta_{t}}=\frac{H_{t 0}}{H_{f}} \ldots \ldots . . .
\end{gathered}
$$

where $\beta_{t}$ is the spread coefficient of the top of rail, $c_{m}$ is the influence factor of the material on the spread (Table 1), $c_{w t}$ is the deformation conformity factor between the web of rail and the top of rail, $w_{f}$ is the proportion between the volume of metal flowing to the cross section and the total volume of metal flow, $G_{v t}$ is the roll gap, $R_{v t}$ is the maximum radius of vertical roll rolling the top of rail, $\varphi$ is the friction factor of box pass.

The width of the top of rail at the exit section $W_{b 1}$ can be calculated by the modified S. Ekelund spread equation
Table 1. The component influence coefficient $m$ of different alloyed steel.

$$
\begin{aligned}
& \text { Steel type } \quad \text { Brand of steel } \quad \text { The component influence coefficient } m \\
& \text { Plain carbon stee } \\
& \text { Ledeburite } \\
& \text { Pearlite-martensite } \\
& \text { Austenite } \\
& \text { Ferrite } \\
& \text { Carbite austenite } \\
& W_{b 1}=c_{m} \cdot c_{w b}\left(\sqrt{4 c_{h}^{2}\left(H_{b 0}+H_{b 1}\right)\left(\frac{l_{b}}{W_{b 0}}\right)+W_{b 0}^{2}+4 c_{h} l_{b}\left(3 H_{b 0}-H_{b 1}\right)}\right. \\
& \left.-2 c_{h}\left(H_{b 0}+H_{b 1}\right)\left(\frac{l_{b}}{W_{b 0}}\right)\right) \text {. } \\
& c_{w b}=1+\frac{\eta_{b}-\eta_{w}}{\eta_{w}} w_{f} \\
& c_{h}=\frac{1.6 \mu_{v b} L_{b}-1.2\left(H_{b 0}-H_{b 1}\right)}{H_{b 0}+H_{b 1}} \\
& l_{b}=\sqrt{R_{v b}\left(H_{b 0}-H_{b 1}\right)}
\end{aligned}
$$

\begin{tabular}{cc} 
Brand of steel & The component influence coefficient $m$ \\
Q195 & 1.0 \\
W18Cr4V & 1.10 \\
GCr15、40Cr、38GMoAl & $1.24 \sim 1.30$ \\
Cr13Ni4Mn9 & 1.40 \\
1Cr17Al & 1.55 \\
Cr15Ni60 & 1.60 \\
\hline
\end{tabular}

where $c_{w b}$ is the deformation conformity factor between the web of rail and the top of rail, $l_{b}$ is the length of contact zone of the base of rail.

In this paper, the critical point is defined as the point on the contact boundary at the exit section. It affects the contact status and the shape of the outgoing workpiece directly, so it is indispensable for determining the mean roll radius.

At the exit cross-section, the critical point $\left(C_{y}, C_{z}\right)$ can be determined by the intersecting point between the stress free surface and the side wall of box pass. So the critical point $\left(C_{y}, C_{z}\right)$ can be obtained from the following equations:

$$
\begin{aligned}
& 2\left(C_{z}+C_{y} \cdot \tan \theta\right)=W_{t 1} . \\
& \frac{H_{f}-C_{y}}{H_{f}}=\frac{2 C_{z}-B_{0}}{B_{f}-B_{0}}
\end{aligned}
$$

When $0<\theta<\alpha$, solving the Eq. (16) and the Eq. (17) yields

$$
\begin{gathered}
C_{z}=\frac{W_{t 1}-\frac{\tan \theta}{\tan \alpha_{t}} \cdot B_{f}}{2\left(1-\frac{\tan \theta}{\tan \alpha_{t}}\right)} \\
C_{y}=\frac{0.5 B_{f}-C_{z}}{\tan \alpha_{t}} \ldots
\end{gathered}
$$

As shown in Eq. (18) and Eq. (19)

when $\theta=0, \quad C_{z}=B_{0} / 2$ and $C_{y}=H_{f}$..........

when $\theta=\alpha, \quad C_{z}=B_{f} / 2 \cdot G_{v t} \cdot \tan \alpha \quad$ and $\quad C_{y}=G_{v t}$

As can be seen in Fig. 2, the little round angle is neglected. Since the small amount of area is neglected, the area of available contact section (hatching zone) $A_{h}$ at the exit section can be determined by

$$
\begin{aligned}
A_{h}= & 2 C_{z} \cdot H_{f}-\left(C_{z}-\frac{B_{0}}{2}\right)\left(H_{f}-C_{y}\right) \\
& +C_{z} \cdot\left(W_{t 1}-G_{h}\right) \tan \alpha_{h 1}-\left(C_{z}-\frac{G_{h}}{2}\right)^{2} \tan \alpha_{h 1}
\end{aligned}
$$


If the profile of the top of rail at the exit cross-section is simplified as a rectangular cross-section which width is $2 C_{z}$ and height is $\overline{H_{t 1}}$, then the area of equivalent contact section (rectangular zone $\left.a^{\prime} b^{\prime} c^{\prime} d^{\prime}\right) A_{a^{\prime} b^{\prime} c^{\prime} d^{\prime}}$ can be obtained by

$$
A_{a^{\prime} b^{\prime} c^{\prime} d^{\prime}}=A_{h}=2 C_{z} \cdot \overline{H_{t 1}}
$$

The equivalent height of outgoing workpiece $\overline{H_{t 1}}$ can be calculated by

$$
\begin{aligned}
\overline{H_{t 1}}=\overline{G_{v t}}=\frac{A_{h}}{2 C_{z}}= & \frac{1}{2}\left(H_{f}+C_{y}\right)+\frac{B_{0}}{4 C_{z}}\left(H_{f}-C_{y}\right) \\
& +\left(\frac{W_{t 1}}{2}-\frac{C_{z}}{2}-\frac{G_{h}^{2}}{8 C_{z}}\right) \tan \alpha_{h 1} \ldots
\end{aligned}
$$

where $G_{h}$ is the horizontal roll gap, $\alpha_{h 1}$ is the oblique angle of the right flank of horizontal roll.

The equivalent radius of the vertical roll for rolling the top of rail $\overline{R_{v t}}$ can be obtained by

$$
\overline{R_{v t}}=R_{v t}+G_{v t}-\overline{G_{v t}}
$$

So the vertical roll for rolling the top of rail can be simplified as a flat roll which radius is $\overline{R_{v t}}$ and the gap is $\overline{G_{v}}$.

As shown in Fig. 3, the profile of the base of rail at the exit cross-section can be simplified as a equivalent rectangular cross-section which width is $W_{b 1}$ and height is $H_{b 1}$. The equivalent height $H_{b 1}$ can be expressed as

$$
H_{b 1}=\overline{G_{v b}}=G_{v b}+\left(\frac{W_{b 1}}{4}-\frac{G_{h}^{2}}{4 W_{b 1}}\right) \tan \alpha_{h 2}
$$

Where $\alpha_{h 2}$ is the oblique angle of the left flank of horizontal roll.

So, the simplified model of rail rolling can be shown as Fig. 4.

Based on the simplified model of rail universal rolling mentioned above, there are 5 contact zone existing in the deformed workpiece (Fig. 5): (1) the contact zone I between the vertical roll and the top of rail; (2) the contact zone II between the horizontal roll and the web of rail; (3) the contact zone III between the vertical roll and the base of rail; (4) the contact zone IV between the horizontal roll and the top of rail; (5) the contact zone $\mathrm{V}$ between the horizontal roll and the top of rail.

\section{Neutral Angle of Horizontal Roll and Vertical Roll}

The neutral angle is an important parameter since it de- fines the relative-movement condition between the roll and the deformed metal in the deformation zone, and it has to be considered in computing the relative friction between the roll and the deformed metal.

\subsection{Determination of the Neutral Angle of the Vertical Roll}

According to the research of W. Zhang, ${ }^{5)}$ the neutral angle of the vertical roll can be derived from the equilibrium conditions of the torque acting on the vertical roll. the friction torque $M_{v b}$ acting on the vertical roll from the base of rail can be expressed as

$$
M_{v b}=\overline{p_{v b} W_{b}} R_{v b} \mu_{v b} \gamma_{v b}-\overline{p_{v b} W_{b}} R_{v b} \mu_{v b}\left(\alpha_{v b}-\gamma_{v b}\right) \ldots
$$

where $\overline{W_{b}}$ is the mean width of the base of rail in deformation zone.

The friction torque $M_{0 b}$ acting on the vertical roll from the bearing of the vertical roll for rolling the base of rail can be obtained by

$$
M_{0 b}=-\overline{p_{v b} W_{b}} \alpha_{v b} \mu_{0 b} R_{0 b}
$$

Since the vertical roll is driven, the equilibrium equation for the torque acting on the vertical roll can be shown as

$$
M_{0 b}+M_{v b}=0 \text {. }
$$

Solving the Eq. (29), the neutral angle of vertical roll for rolling the base of rail $\gamma_{v b}$ can be shown as

$$
\gamma_{v b}=\frac{\alpha_{v b}}{2}\left(1+\frac{\mu_{0 v b} R_{0 v b}}{\mu_{v b} R_{v b}}\right) .
$$

By the same method mentioned above, the neutral angle of vertical roll for rolling the top of rail $\gamma_{v t}$ can be shown as

$$
\gamma_{v t}=\frac{\alpha_{v t}}{2}\left(1+\frac{\mu_{0 t} R_{0 t}}{\mu_{v t} R_{v t}}\right)
$$

\subsection{The Neutral Angle of the Horizontal Roll}

The neutral angle of horizontal roll can be obtained by the law of constant volume of metal flow (Fig. 6)

$$
H_{n} V_{h} \cos \gamma_{h}=H_{w 1} V_{1}
$$

where $H_{n}$ is the height of the web of rail at the neutral plane of deformation zone, it can be shown as

$$
H_{n}=H_{w 1}+2 R_{h}\left(1-\cos \gamma_{h}\right)
$$

The velocity of rail at the exit section can be shown as

$$
V_{1}=V_{h} \delta_{w}
$$

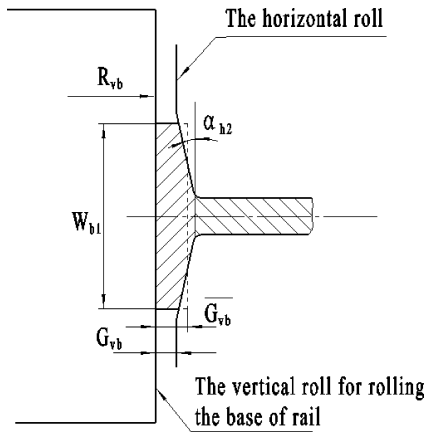

Fig. 3. Schematic plan of simplifying the vertical roll.

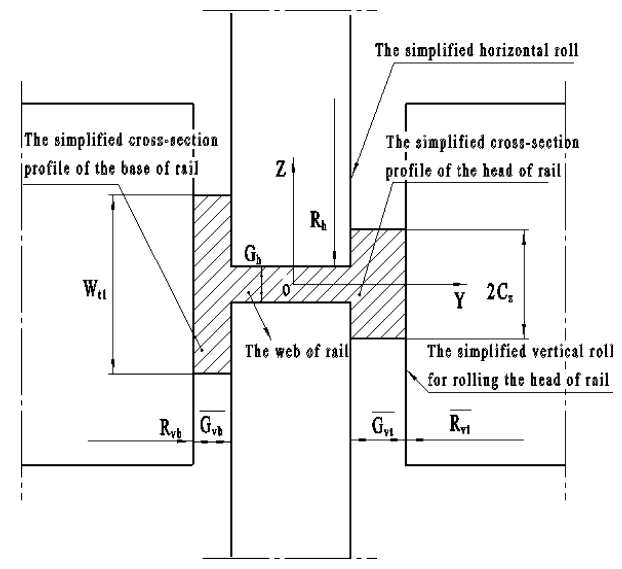

Fig. 4. The simplification of the cross-section of the base of rail

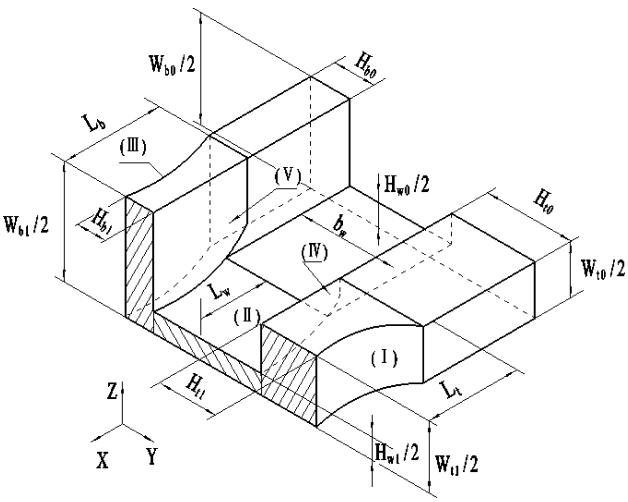

Fig. 5. The simplified geometrical model of the rail universal rolling. 


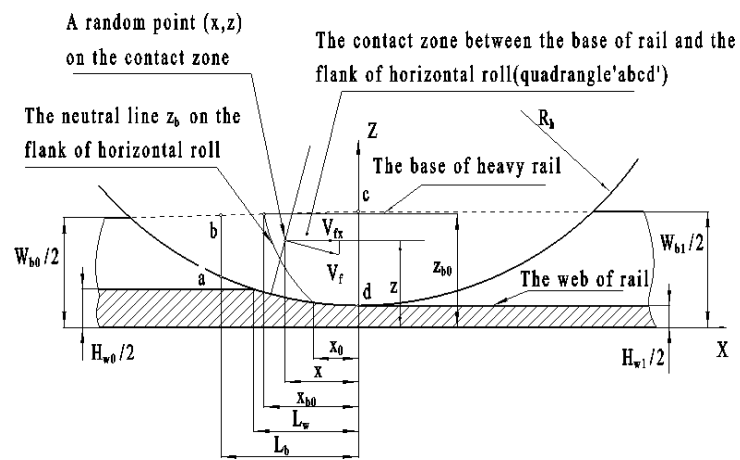

Fig. 6. The neutral line on the flank of horizontal roll.

A new equation can be obtained by Eqs. (32)-(34)

$$
2 R_{h} \cos ^{2} \gamma_{h}-\left(H_{w 1}+2 R_{h}\right) \cos \gamma_{h}+H_{w 1} \gamma_{w}=0
$$

The Eq. (36) and Eq. (37) under mentioned can be used to simplify the Eq. (35)

$$
\begin{aligned}
& \cos ^{2} \gamma_{h} \approx 1-\gamma_{h}^{2} . \\
& \cos \gamma_{h} \approx 1-\gamma_{h}^{2} / 2
\end{aligned}
$$

So the neutral angle of horizontal roll can be obtained from

$$
\gamma_{h}=\sqrt{\frac{\left(\delta_{w}-1\right)}{\left(R_{h} / H_{w 1}\right)-1 / 2}} \approx \sqrt{\frac{H_{w 1}}{R_{h}}\left(\delta_{w}-1\right)} .
$$

\section{Forward Slip Coefficient of the Web}

\subsection{The Equation of Neutral Line on the Flank of Horizontal Roll}

In the dissertation of Zhe Wang ${ }^{2}$ and Xiao-guang $\mathrm{Jin}^{3)}$ for studying the forward slip coefficient of H-beam universal rolling, the concept "neutral line on the flank of horizontal roll" was proposed. For determining the equation of neutral line, a random point, which is on the contact zone between the flank of horizontal roll and the base of rail, has been chosen (Fig. 6).

On the flank of horizontal roll, the velocity of this point $V_{f}$ can be obtained from

$$
V_{f}=\frac{V_{h}}{R_{h}} \sqrt{x^{2}+\left(\frac{H_{w 1}}{2}+R_{h}-y\right)^{2}}
$$

The horizontal component of the velocity $V_{f}$ can be shown as

$$
V_{f x}=\frac{V_{h}}{R_{h}}\left(\frac{H_{w 1}}{2}+R_{h}-y\right) .
$$

On the surface of the base of rail, the velocity of this point $V_{b}$ can be determined by the condition of constant flow volume of metal

$$
V_{b x}=\frac{V_{1} H_{b 1}}{H_{b x}}=\frac{V_{h} \delta_{w} H_{b 1}}{H_{b x}}
$$

where $H_{b x}$ is the height of the base of rail at the cross-section where this point locates, $H_{b 1}$ is the height of the base of rail at the exit section, $V_{1}$ is the velocity of rail at the exit section.

As can be seen in Fig. 7, $H_{b x}$ can be expressed as

$$
H_{b x}=H_{b 1}+\left(R_{v b}-\sqrt{R_{v b}^{2}-x^{2}}\right)
$$

Substituting Eq. (42) into Eq. (41) yields

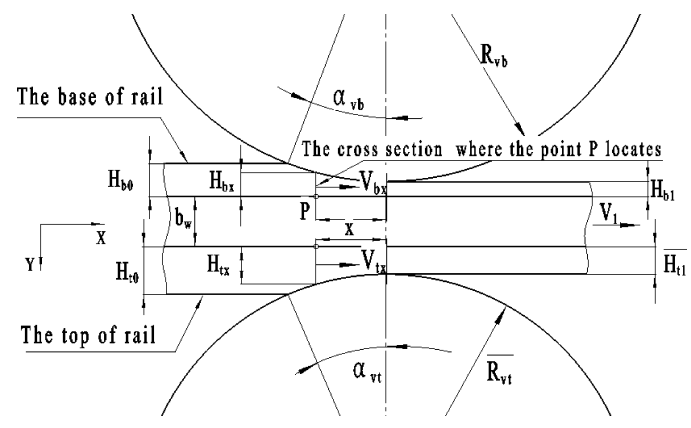

Fig. 7. The velocity of the base and top of rail on the flank of horizontal roll.

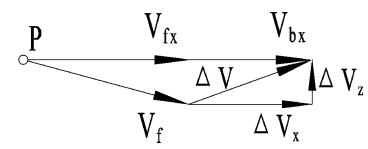

Fig. 8. The velocity vector of the point P.

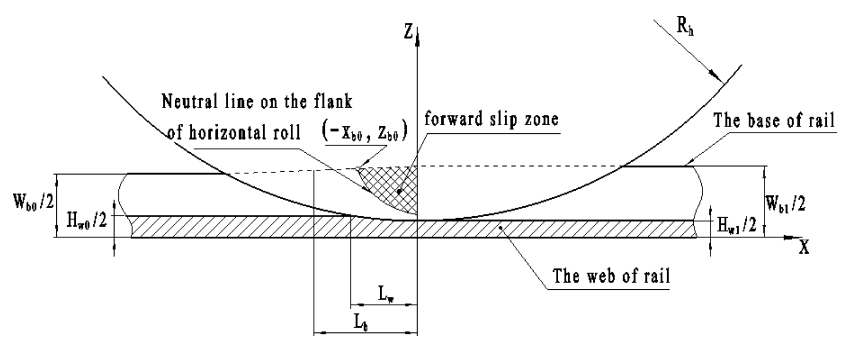

Fig. 9. Schematic plan of forward slip zone on the flank of horizontal $\operatorname{roll}\left(\delta_{w} \leq 1\right)$.

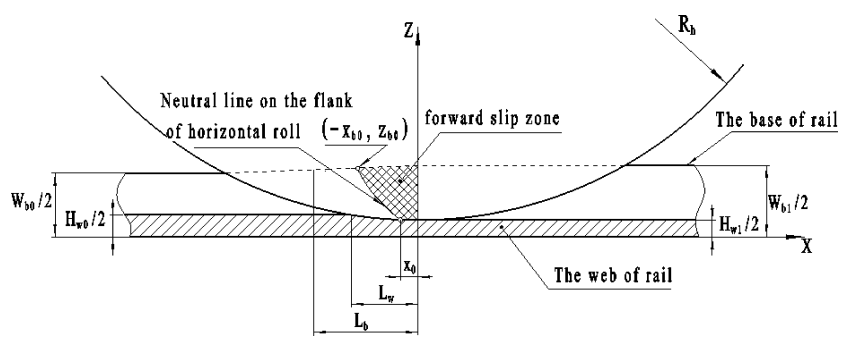

Fig. 10. Schematic plan of forward slip zone on the flank of horizontal $\operatorname{roll}\left(\delta_{w}>1\right)$.

$$
V_{b x}=\frac{V_{h} \delta_{w} H_{b 1}}{H_{b 1}+\left(R_{v b}-\sqrt{R_{v b}^{2}-x^{2}}\right)}
$$

As can be seen in Fig. 8, the relative velocity of this point between the flank of horizontal roll and the base of rail $\Delta V_{x}$ can be shown as

$$
\Delta V_{x}=V_{b x}-V_{f x}
$$

Since the relative velocity $\Delta V_{x}$ of any point on the neutral line is 0 , the equation of neutral line on the left flank of horizontal roll can be expressed as

$$
\begin{aligned}
& z_{b}=\frac{H_{w 1}}{2}+R_{h}-\frac{\delta_{w} H_{b 1} R_{h}}{H_{b 1}+\left(R_{v b}-\sqrt{R_{v b}^{2}-x^{2}}\right)} \\
& \approx \frac{H_{w 1}}{2}+R_{h}-\frac{\delta_{w} H_{b 1} R_{h}}{H_{b 1}+x^{2} / D_{v b}}
\end{aligned}
$$

So, the intersecting point $\left(x_{b 0}, y_{b 0}\right)$ between neutral line and the boundary of the base of rail are expressed as (Figs. 9, 10).

$$
z_{b 0}=\left(W_{b 0}+W_{b 1}\right) / 4
$$




$$
\begin{aligned}
& x_{b 0}=\sqrt{\frac{H_{b 1} \cdot D_{v b}\left[W_{b 0}-H_{w 1}-D_{h}\left(1-\delta_{w}\right)\right]}{D_{h}-W_{b 0}+H_{w 1}}} \\
& \approx \sqrt{\frac{H_{b 1} \cdot D_{v b}\left(W_{b 0}-H_{w 1}\right)}{D_{h}-W_{b 0}+H_{w 1}}}
\end{aligned}
$$

By the same method mentioned above, the neutral line on the right flank of horizontal roll can be shown as

$$
z_{t} \approx \frac{H_{w 1}}{2}+R_{h}-\frac{\delta_{w} \overline{H_{t 1}} R_{h}}{\overline{H_{t 1}}+x^{2} / \overline{D_{v t}}}
$$

The intersecting point $\left(x_{t 0}, y_{t 0}\right)$ between neutral line and the boundary of top of rail are expressed as

$$
\begin{aligned}
& z_{t 0}=\left(W_{t 0}+W_{t 1}\right) / 4 \ldots \ldots \ldots \ldots \ldots \ldots \ldots \ldots \ldots \ldots \ldots \ldots \ldots \\
& x_{t 0}=\sqrt{\frac{H_{b 1} \cdot D_{v b}\left[W_{b 0}-H_{w 1}-D_{h}\left(1-\delta_{w}\right)\right]}{D_{h}-W_{b 0}+H_{w 1}}} \\
& \approx \sqrt{\frac{H_{b 1} \cdot D_{v b}\left(W_{b 0}-H_{w 1}\right)}{D_{h}-W_{b 0}+H_{w 1}}}
\end{aligned}
$$

\subsection{The Area of Forward Slip Zone and Backward- slip Zone on the Flank of Horizontal Roll}

As can be seen Fig. 9 and Fig. 10, the total area of contact zone between the flank of horizontal roll and the base of rail $A_{f b}$ can be shown as

$$
\begin{aligned}
A_{f b} & =\int_{0}^{L_{b}}\left[\frac{W_{b 0}-H_{w 1}}{2}-\left(R_{h}-\sqrt{R_{h}^{2}-x^{2}}\right)\right] d x \\
& =\frac{L_{b}}{2} \cdot\left[\left(W_{b 0}-H_{w 1}\right)-\left(R_{h}-\sqrt{R_{h}^{2}-L_{b}^{2}}\right)\right]
\end{aligned}
$$

By the same method mentioned above, the area of contact zone between the flank of horizontal roll and the top of rail $A_{f t}$ can be shown as

$$
\begin{aligned}
A_{f t} & =\int_{0}^{L_{t}}\left[\frac{W_{t 0}-H_{w 1}}{2}-\left(R_{h}-\sqrt{R_{h}^{2}-x^{2}}\right)\right] d x \\
& =\frac{L_{t}}{2} \cdot\left[\left(W_{t 0}-H_{w 1}\right)-\left(R_{h}-\sqrt{R_{h}^{2}-L_{b}^{2}}\right)\right]
\end{aligned}
$$

where $L_{b}, L_{t}$ is the length of deformation zone in rolling the base of rail and top of rail (Fig. 5), respectively.

\subsubsection{The Area of Forward Slip Zone on the Flank of Horizontal Roll $\left(\delta_{w} \leq 1\right)$}

As can be seen in Fig. 9, when $\delta_{w} \leq 1$ the neutral line and forward slip zone on the left flank of horizontal roll have been indicated.

If $x_{b 0}<L_{b}$, the area of forward slip zone on the left flank of horizontal roll $A_{f b}^{\prime}$ can be shown as

$$
\begin{aligned}
A_{f b}^{\prime} & =\int_{0}^{x_{b 0}}\left(\frac{W_{b 0}-H_{w 1}}{2}-R_{h}+\frac{\delta_{w} R_{h}}{1+x^{2} /\left(H_{b 1} \cdot D_{v b}\right)}\right) d x \\
& =\frac{W_{b 0}-H_{w 1}}{2} x_{b 0}-R_{h} x_{b 0}\left(1-\delta_{w}\right) \ldots \ldots \ldots \ldots \ldots \ldots \ldots \ldots \ldots \ldots \ldots \ldots \ldots
\end{aligned}
$$

By the same method, when $x_{t 0}<L_{t}$ the area of forward slip zone on the right flank of horizontal roll $A_{f t}^{\prime}$ can be shown as

$$
\begin{aligned}
A_{f t}^{\prime} & =\int_{0}^{x_{t 0}}\left(\frac{W_{t 0}-H_{w 1}}{2}-R_{h}+\frac{\delta_{w} R_{h}}{1+x^{2} /\left(\overline{H_{t 1}} \cdot \overline{D_{v t}}\right)}\right) d x \\
& =\frac{W_{t 0}-H_{w 1}}{2} x_{t 0}-R_{h} x_{t 0}\left(1-\delta_{w}\right)
\end{aligned}
$$

If $x_{b 0} \geq L_{b}$, the area of forward slip zone on the left flank of horizontal roll $A_{f b}^{\prime}$ can be shown as

$$
A_{f b}^{\prime}=\frac{W_{b 0}-H_{w 1}}{2} L_{b}-R_{h} L_{b}\left(1-\delta_{w}\right)
$$

By the same method, when $x_{t 0} \geq L_{t}$ the area of forward slip zone on the left flank of horizontal roll $A_{f t}^{\prime}$ can be shown as

$$
A_{f t}^{\prime}=\frac{W_{t 0}-H_{w 1}}{2} L_{t}-R_{h} L_{t}\left(1-\delta_{w}\right)
$$

4.2.2. The Area of Forward Slip Zone on the Flank of Horizontal Roll $\left(\delta_{w}>1\right)$

As can be seen in Fig. 10, when $\delta_{w}>1$ the neutral line and forward slip zone on the left flank of horizontal roll have been indicated.

If $x_{b 0}<L_{b}$, the area of forward slip zone on the left flank of horizontal roll $A_{f b}^{\prime}$ can be shown as

$$
\begin{aligned}
A_{f b}^{\prime}= & x_{0} \cdot \frac{W_{b 0}-H_{w 1}}{2} \\
& +\int_{x_{0}}^{x_{b 0}}\left(\frac{W_{b 0}-H_{w 1}}{2}-R_{h}+\frac{\delta_{w} R_{h}}{1+x^{2} /\left(H_{b 1} \cdot D_{v b}\right)}\right) d x
\end{aligned}
$$

where $x_{0}$ is the distance from the bottom of neutral line to the outgoing cross-section, it can be shown as

$$
x_{0}=R_{h} \gamma_{h}
$$

By the same method, when $x_{t 0}<L_{t}$ the area of forward slip zone on the right flank of horizontal roll $A_{f t}^{\prime}$ can be shown as

$$
\begin{aligned}
A_{f t}^{\prime}= & x_{0} \cdot \frac{W_{t 0}-H_{w 1}}{2} \\
& +\int_{x_{0}}^{x_{t 0}}\left(\frac{W_{t 0}-H_{w 1}}{2}-R_{h}+\frac{\delta_{w} R_{h}}{1+x^{2} /\left(\overline{H_{t 1}} \cdot \overline{D_{v t}}\right)}\right) d x
\end{aligned}
$$

On the contrary, when $x_{b 0} \geq L_{b}$ the area of forward slip zone on the left flank of horizontal roll $A_{f b}^{\prime}$ can be shown as

$$
\begin{aligned}
A_{f b}^{\prime}= & x_{0} \cdot \frac{W_{b 0}-H_{w 1}}{2} \\
& +\int_{x_{0}}^{L_{b}}\left(\frac{W_{b 0}-H_{w 1}}{2}-R_{h}+\frac{\delta_{w} R_{h}}{1+x^{2} /\left(H_{b 1} \cdot D_{v b}\right)}\right) d x
\end{aligned}
$$

By the same method, when $x_{t 0} \geq L_{t}$ the area of forward slip zone on the left flank of horizontal roll $A_{f t}^{\prime}$ can be shown as

$$
\begin{aligned}
A_{f t}^{\prime}= & x_{0} \cdot \frac{W_{t 0}-H_{w 1}}{2} \\
& +\int_{x_{0}}^{L_{t}}\left(\frac{W_{t 0}-H_{w 1}}{2}-R_{h}+\frac{\delta_{w} R_{h}}{1+x^{2} /\left(\overline{H_{t 1}} \cdot \overline{D_{v t}}\right)}\right) d x \ldots .
\end{aligned}
$$




\subsection{The Area of Forward Slip Zone in the Deforma- tion Zone of the Web of Rail}

The total area of contact zone $A_{w}$ can be shown as

$$
A_{w}=b_{w} \cdot L_{w}
$$

when $\delta_{w} \leq 1$, the area of forward slip zone $A_{w}^{\prime}$ is 0 . So, the area of backward-slip zone $A_{w}^{\prime \prime}$ can be obtained by

$$
A_{w}^{\prime \prime}=A_{w}=b_{w} \cdot L_{w}
$$

Consequently, when $\delta_{w} \leq 1$, the deformation zone is complete backward-slip zone.

When $\delta_{w}<1$, the area of forward slip zone can be obtained by

$$
A_{w}^{\prime}=b_{w} R_{h} \gamma_{h}=b_{w} \sqrt{H_{w 1} R_{h}\left(\delta_{w}-1\right)}
$$

\subsection{The Horizontal Resultant Force Acting on the De- formed Workpiece}

The horizontal resultant force $X_{v}$ acting on the top and base of rail from the vertical roll can be obtained by

$$
\begin{aligned}
X_{v}= & X_{v t}+X_{v b}=W_{t 0} \overline{p_{v t}} \mu_{v t} L_{t}\left(1-\frac{2 \gamma_{v t}}{\alpha_{v t}}-\frac{\tan \left(\alpha_{v t} / 2\right)}{\mu_{v t}}\right) \\
& +W_{b 0} \overline{p_{v b}} \mu_{v b} L_{b}\left(1-\frac{2 \gamma_{v b}}{\alpha_{v b}}-\frac{\tan \left(\alpha_{v b} / 2\right)}{\mu_{v b}}\right)
\end{aligned}
$$

The horizontal resultant force $X_{f b}$ acting on the base of rail from the flank of horizontal roll can be obtained by

$$
X_{f b}=2 \overline{p_{h b}} \mu_{h b}\left(A_{f b}^{\prime \prime}-A_{f b}^{\prime}\right)=2 \overline{p_{h b}} \mu_{h b}\left(A_{f b}-2 A_{f b}^{\prime}\right)
$$

For simplifying the deriving process, the horizontal resultant force $X_{f t}$ acting on the top of rail from the flank of horizontal roll can be obtained by

$$
\frac{X_{f t}}{X_{f b}}=\frac{\overline{p_{h t}} \mu_{h t}\left(A_{f t}-2 A_{f t}^{\prime}\right)}{\overline{p_{h b}} \mu_{h b}\left(A_{f b}-2 A_{f b}^{\prime}\right)}=\rho
$$

where the coefficient $\rho$ is a proportion factor about horizontal resultant force $X_{f t}$ and $X_{s b}$. Then

$$
X_{f}=X_{f t}+X_{f b}=(1+\rho) X_{f b}
$$

If $\delta_{w} \leq 1$, the horizontal resultant force $X_{w}$ acting on the web of rail from the horizontal roll can be obtained by

$$
\begin{aligned}
X_{w} & =2 b_{w}\left(\overline{p_{h}} L_{w} \mu_{h w}-\overline{p_{h}} \frac{L_{w}}{\cos \left(\alpha_{h} / 2\right)} \sin \left(\frac{\alpha_{h}}{2}\right)\right) \\
& \approx 2 b_{w} \overline{p_{h}} L_{w} \mu_{h w}\left(1-\frac{\alpha_{h}}{2 \mu_{h w}}\right)
\end{aligned}
$$

If $\delta_{w}>1$, the horizontal resultant force $X_{w}$ can be obtained by

$$
X_{w}=2 \overline{p_{h}} \mu_{h w}\left(A_{w}-2 A_{w}^{\prime}\right)-2 b_{w} \overline{p_{h}} L_{w} \mu_{h w} \tan \left(\frac{\alpha_{h}}{2}\right)
$$

\subsection{The Forward Slip Coefficient of the Web of Rail $\left(\delta_{w} \leq 1\right)$}

The equilibrium condition of horizontal resultant force acting on the deformed workpiece can be shown as

$$
\sum X=X_{w}+X_{f}+X_{v}=0
$$

when $x_{b 0}<L_{b}$, solving the Eq. (71) yields

$$
\begin{gathered}
\delta_{w}=1-\frac{\left(W_{b 0}-H_{w 1}\right)-a^{2 / 3}}{D_{h}} \ldots \ldots \ldots \ldots \ldots . . . \\
a=\frac{X_{w}+X_{v t}+X_{v b}-(1+\rho) \overline{p_{h b}} L_{b} \mu_{h b} W_{b 0}-H_{w 1}}{2 \overline{p_{h b}} \mu_{h b} \sqrt{\frac{H_{b 1} \cdot D_{v b}}{D_{h}-W_{b 0}+H_{w 1}}}(1+\rho)} \\
-\frac{L_{b}}{2}\left[W_{b 0}-H_{w 1}-\left(R_{h}-\sqrt{R_{h}^{2}-L_{b}^{2}}\right)\right] \ldots \ldots \ldots \ldots
\end{gathered}
$$

when $x_{b 0} \geq L_{b}$, solving the Eq. (71) yields

$$
\delta_{w}=1-\frac{1}{2 D_{h}}\left[\frac{X_{w}+X_{v}}{(1+\rho) \overline{p_{h b}} \mu_{h b} L_{b}}+W_{b 0}-H_{w 1}-\left(R_{h}-\sqrt{R_{h}^{2}-L_{b}^{2}}\right)\right]
$$

4.6. The Forward Slip Coefficient of the Web of Rail $\left(\delta_{w}>1\right)$

When $x_{b 0}<L_{b}$, solving the Eq. (71) yields

$$
\begin{aligned}
\delta_{w} & =1+\frac{1}{b}\left[\frac{\overline{p_{h}} b_{w} L_{w} \mu_{h w}}{\overline{p_{h b}} \mu_{h b}}\left(1-\frac{\alpha_{h}}{2 \eta_{h w}}\right)+(1+\rho) L_{f}\left(W_{b 0}-H_{w 1}\right)\right. \\
& \left.\times\left(1-\frac{2}{L_{f}} \sqrt{\frac{H_{b 1} \cdot D_{v b}\left(W_{b 0}-H_{w 1}\right)}{D_{h}-W_{b 0}+H_{w 1}}}\right)+\frac{X_{v}}{\overline{p_{h b}} \mu_{h b}}\right] \ldots \ldots \ldots . .(75)
\end{aligned}
$$

where $b$ is expressed as

$$
\begin{aligned}
& b=(1+\rho)\left(50 \sqrt{\frac{\left(0.02 D_{h}+W_{b 0}-H_{w 1}\right)^{2} H_{b 1} \cdot D_{v b}}{D_{h}-W_{b 0}+H_{w 1}}}\right. \\
& \left.-0.28 R_{h} \sqrt{R_{h} H_{w 1}}-50\left(W_{b 0}-H_{w 1}\right) \sqrt{\frac{H_{b 1} \cdot D_{v b}\left(W_{b 0}-H_{w 1}\right)}{D_{h}-W_{b 0}+H_{w 1}}}\right) \\
& +\frac{14 \overline{p_{h}} b_{w} \mu_{h w}}{\overline{p_{h b}} \mu_{h b}} \sqrt{H_{w 1} R_{h}}
\end{aligned}
$$

when $x_{b 0} \geq L_{b}$, solving the Eq. (71) yields

$$
\begin{aligned}
& \delta_{w}=1+\left\{\frac{\overline{p_{h}} b_{w} L_{w} \mu_{h w}}{\overline{p_{h b}} \mu_{h b}}\left(1-\frac{\alpha_{h}}{2 \mu_{h w}}\right)+(1+\rho) L_{f}\left(W_{b 0}-H_{w 1}\right)\right. \\
& \quad \times\left(1-\frac{2}{L_{f}} \sqrt{\left.\left.\frac{H_{b 1} \cdot D_{v b}\left(W_{b 0}-H_{w 1}\right)}{D_{h}-W_{b 0}+H_{w 1}}\right)+\frac{X_{v}}{\overline{p_{h t}} \mu_{h t}}\right\} /}\right. \\
& \left\{2(1+\rho)\left(R_{h} L_{f}-0.14 R_{h} \sqrt{H_{w 1} R_{h}}\right)+\frac{14 \overline{p_{h}} b_{w} \mu_{h w}}{\overline{p_{h b}} \mu_{h b}} \sqrt{H_{w 1} R_{h}}\right\}
\end{aligned}
$$

\section{Forward Slip Coefficient of the Top and Base of Rail}

According to the condition of constant flow volume of metal, the following equation can be obtained (Fig. 7)

$$
V_{v b}=\frac{V_{1} H_{b 1}}{\left(H_{b 1}+R_{v b}\left(1-\cos \gamma_{v b}\right)\right) \cos \gamma_{v b}}
$$

So the forward coefficient of the base of rail can be shown as 


$$
\delta_{v b}=\frac{V_{1}}{V_{v b}}=\cos \gamma_{v b}\left[\left(1-\cos \gamma_{v b}\right) \frac{R_{v b}}{H_{b 1}}+1\right] \approx 1+\left(\frac{R_{v b}}{2 H_{b 1}}-1\right) \gamma_{v b}^{2}
$$

By the same method, the forward slip coefficient of the top of rail can be expressed as

$$
\delta_{v t}=\cos \gamma_{v t}\left[\left(1-\cos \gamma_{v t}\right) \frac{\overline{R_{v t}}}{\overline{H_{t 1}}}+1\right]=1+\left(\frac{\overline{R_{v t}}}{2 \overline{H_{t 1}}}-1\right) \gamma_{v t}^{2}
$$

\section{The Numerical Simulation of Rail Universal Rolling}

For verifying the forward slip theoretical model of rail universal rolling, the three-dimensional solid model of rail universal rolling are built by the software SolidWorks 2005 according to corresponding equipment parameters. The universal rolling process of $60 \mathrm{~kg} / \mathrm{m}$ heavy rail and $18 \mathrm{~kg} / \mathrm{m}$ light rail are simulated by the Rigid-plastic FEM software DEFORM-3D V5.0.

The rigid-plastic FEM model of rail universal rolling is built as Fig. 11 for the symmetry of workpiece. The horizontal is defined as a rigid body, the workpiece is defined as rigid-plastic body, and the driven vertical roll are jacketed on the supporting spindle and they are defined as elastic body, the supporting spindles are defined as rigid body. The size of initial workpiece is shown as Fig. 11. The FEM model of universal mill is shown as Fig. 12(a). For biting into the gap easily, the head of initial workpieces are cut as Figs. 12(b) and 12(c). So the web of rail will contact the horizontal roll before it contact the vertical roll.

The material of heavy rail is rare-earth rail steel $\mathrm{BNbRe}$, and its resistance to the deformation can be obtained by the physical simulation experiments, the details can be seen in Ref. 18). The material of light rail is plain carbon steel Q235, and its resistance to the deformation can be obtained by the Ref. 19). The chemical composition of the heavy rail steel and light rail steel are shown in Table $\mathbf{2}$ and Table 3 respectively.

The rolling schedule of $60 \mathrm{~kg} / \mathrm{m}$ heavy rail universal rolling and $18 \mathrm{~kg} / \mathrm{m}$ light rail universal rolling are shown as Table 4 and Table 5.

The coefficient of heat transfer for convection between the workpiece and the environment is chosen as $0.02 \mathrm{~N} /\left(\mathrm{s} \cdot \mathrm{mm} \cdot{ }^{\circ} \mathrm{C}\right)$, and the coefficient of heat transfer for contact between the workpiece and the roll is chosen as $11 \mathrm{~N} /\left(\mathrm{s} \cdot \mathrm{mm} \cdot{ }^{\circ} \mathrm{C}\right)$. The conversion coefficient from mechan- ical energy to heat energy is chosen as 0.9 . The environment temperature is defined as $25^{\circ} \mathrm{C}$, and the initial temperature of heavy rail is defined as $1150^{\circ} \mathrm{C}$. The friction type is defined as shear friction and the friction coefficient of heavy rail universal rolling is chosen as 0.25 , and the friction coefficient of light rail universal rolling is chosen as 0.35 .

A part of numerical simulation result is shown as Figs. 13-16. The velocity of workpiece No. $2-1$ in the $18 \mathrm{~kg} / \mathrm{m}$ light rail universal rolling is shown as Fig. 13, and the corresponding velocity of vertical rolls in the $18 \mathrm{~kg} / \mathrm{m}$ light rail universal rolling are shown as Figs. 14(a) and 14(b). The velocity of workpiece in the pass UR1 during the $60 \mathrm{~kg} / \mathrm{m}$ heavy rail rolling is shown as Fig. 15, and the velocity of vertical rolls in pass UR1 during the $60 \mathrm{~kg} / \mathrm{m}$ heavy rail rolling are shown as Figs. 16(a) and 16(b). According to the

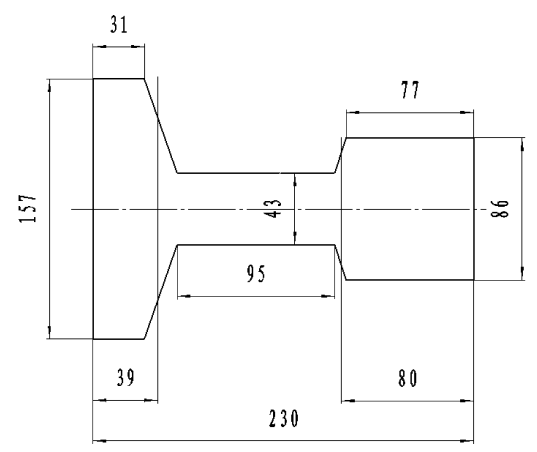

(a) The size of initial workpiece for rolling the $60 \mathrm{~kg} / \mathrm{m}$ heavy rail

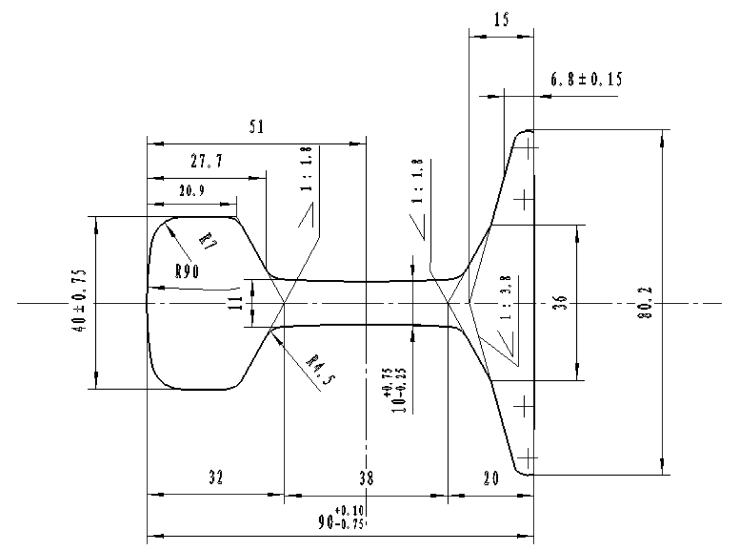

(b) The size of initial workpiece for light rail universal rolling experiments

Fig. 11. The size of initial workpieces for rail universal rolling.

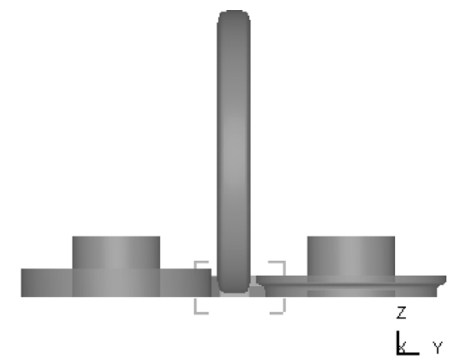

(a)The pass schedule of rail universal rolling

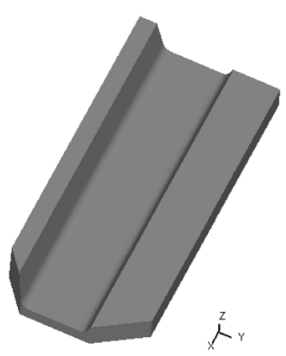

(b) The initial workpiece of $60 \mathrm{~kg} / \mathrm{m}$ heavy rail

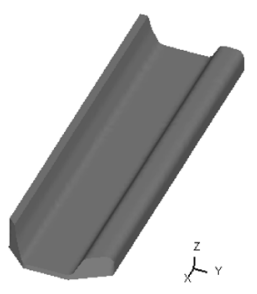

(c) The initial workpiece of $18 \mathrm{~kg} / \mathrm{m}$ light rail

Fig. 12. The rigid-plastic FEM model of rail universal rolling.

Table 2. The chemical composition range of $60 \mathrm{~kg} / \mathrm{m}$ heavy rail steel BNbRe.

\begin{tabular}{c|c|c|c|c|c|c|c}
\hline $\begin{array}{c}\text { Chemical } \\
\text { composition }\end{array}$ & $\mathrm{C}$ & $\mathrm{Si}$ & $\mathrm{Mn}$ & $\mathrm{P}$ & $\mathrm{S}$ & $\mathrm{Nb}$ & $\mathrm{Re}$ \\
\hline Range (\%) & $0.7 \sim 0.82$ & $0.6 \sim 0.9$ & $0.9 \sim 1.2$ & $\leqslant 0.04$ & $\leqslant 0.04$ & $0.02 \sim 0.05$ & $0.02 \sim 0.05$ \\
\hline
\end{tabular}

Table 3. The chemical composition of light rail steel Q235.

\begin{tabular}{l|c|c|c|c|c}
\hline $\begin{array}{c}\text { Chemical } \\
\text { composition }\end{array}$ & $\mathrm{C}$ & $\mathrm{Si}$ & $\mathrm{Mn}$ & $\mathrm{P}$ & $\mathrm{S}$ \\
\hline Content (\%) & 0.17 & 0.21 & 0.83 & 0.019 & 0.012 \\
\hline
\end{tabular}


ISIJ International, Vol. 49 (2009), No. 3

Table 4. The rolling schedule for producing $60 \mathrm{~kg} / \mathrm{m}$ heavy rail.

\begin{tabular}{|c|c|c|c|c|c|c|c|}
\hline \multirow[b]{2}{*}{ Pass } & \multirow[b]{2}{*}{ Stand } & \multirow{2}{*}{$\begin{array}{l}\text { Horizontal roll gap } \\
\qquad(\mathrm{mm})\end{array}$} & \multicolumn{3}{|c|}{ Reduction(mm) } & \multirow{2}{*}{$\begin{array}{l}\text { Rolling } \\
\text { velocity } \\
(\mathrm{mm} / \mathrm{s})\end{array}$} & \multirow{2}{*}{$\begin{array}{l}\text { Horizontal roll } \\
\text { rotating velocity } \\
(\mathrm{rad} / \mathrm{s})\end{array}$} \\
\hline & & & The web of rail & The base of rail & The head of rail & & \\
\hline 1 & UR & 32.0 & 11 & 7.0 & 14.0 & 4910 & 9.043 \\
\hline 2 & $\mathrm{E}$ & 31.5 & 0.5 & -- & -- & 5000 & 13.619 \\
\hline 3 & UR & 24.0 & 7.5 & 4.5 & 11.5 & 5200 & 11.308 \\
\hline 4 & UR & 18.3 & 5.7 & 4.0 & 9.0 & 4950 & 9.128 \\
\hline 5 & $E$ & 18.3 & 0 & -- & -- & 5070 & 13.50 \\
\hline 6 & UF & 16.7 & 1.6 & 1.5 & 2.5 & 5500 & 10.511 \\
\hline
\end{tabular}

Table 5. The rolling schedule for $18 \mathrm{~kg} / \mathrm{m}$ light rail universal rolling experiments.

\begin{tabular}{|c|c|c|c|c|c|c|c|}
\hline \multirow{2}{*}{$\begin{array}{c}\text { Workpiece } \\
\text { No. }\end{array}$} & \multicolumn{3}{|c|}{ Reduction (mm) } & \multirow{2}{*}{$\begin{array}{l}\text { Main motor } \\
\text { speed } \\
\text { (rpm) }\end{array}$} & \multirow{2}{*}{$\begin{array}{c}\text { Horizontal roll } \\
\text { rotating velocity } \\
(\mathrm{rad} / \mathrm{s})\end{array}$} & \multicolumn{2}{|c|}{$\begin{array}{c}\text { Workpiece's } \\
\text { temperature }\left({ }^{\circ} \mathrm{C}\right)\end{array}$} \\
\hline & $\begin{array}{c}\text { The web of } \\
\text { rail }\end{array}$ & $\begin{array}{c}\text { The head of } \\
\text { rail }\end{array}$ & $\begin{array}{c}\text { The base of } \\
\text { rail }\end{array}$ & & & $\begin{array}{c}\text { Tapping } \\
\text { temperature }\end{array}$ & $\begin{array}{l}\text { Initial rolling } \\
\text { temperature }\end{array}$ \\
\hline $1-1,1-2$ & 1.5 & 4.0 & 2.0 & 1200 & 3.9873 & 1050 & 1000 \\
\hline $2-1,2-2$ & 1.5 & 4.5 & 2.0 & 1000 & 3.3228 & 1040 & 995 \\
\hline $3-1,3-2$ & 2.0 & 3.5 & 2.0 & 1000 & 3.3228 & 1060 & 1005 \\
\hline $4-1,4-2$ & 2.0 & 3.0 & 2.0 & 800 & 2.6582 & 1070 & 1015 \\
\hline $5-1,5-2$ & 2.5 & 2.5 & 2.0 & 800 & 2.6582 & 1100 & 1035 \\
\hline $6-1,6-2$ & 2.5 & 2.5 & 2.0 & 600 & 1.9937 & 1100 & 1047 \\
\hline
\end{tabular}

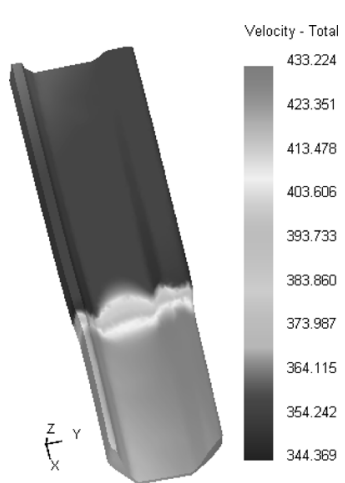

Fig. 13. The velocity of workpiece No. 2-1 in the $18 \mathrm{~kg} / \mathrm{m}$ light rail universal rolling.

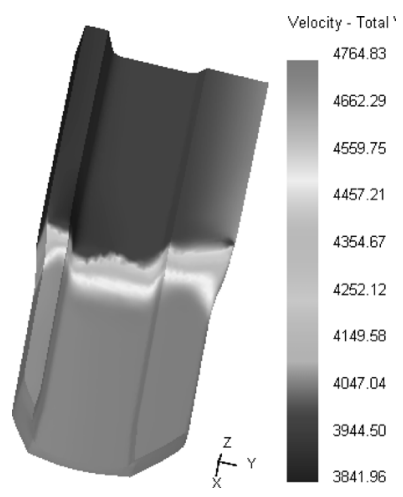

Fig. 15. The velocity of workpiece in pass UR 1 during the $60 \mathrm{~kg} / \mathrm{m}$ heavy rail rolling.

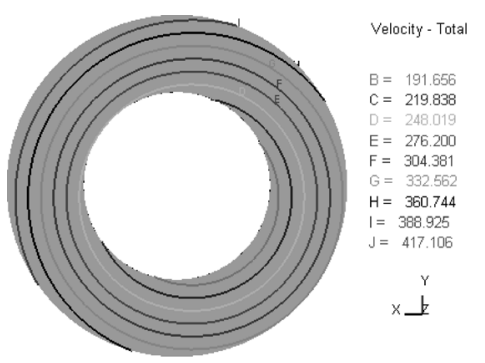

(a) The flat vertical roll

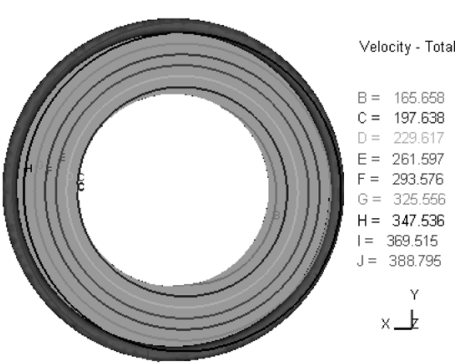

(b)The vertical roll for rolling the top of rail

Fig. 14. The velocity of vertical roll in the workpiece No. $2-1$ in the $18 \mathrm{~kg} / \mathrm{m}$ light rail universal rolling.

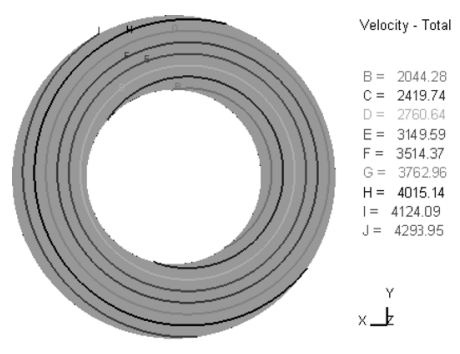

(a) The flat vertical roll

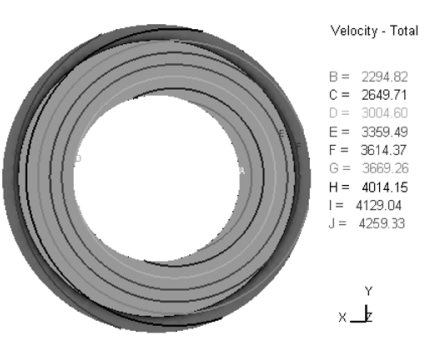

(b)The vertical roll for rolling the top of rail

Fig. 16. The velocity of vertical roll in pass UR 1 during the $60 \mathrm{~kg} / \mathrm{m}$ heavy rail rolling.

numerical simulation results, the forward slip coefficient based on the Rigid-Plastic FEM can be obtained.

\section{The Experiments of Light Rail Universal Rolling}

The light rail universal rolling experiments are accomplished by the three-stand universal mills in the Yanshan University Rolling Laboratory. As can be seen in Fig. 17, 
the main experimental equipments are the data acquisition system, the infrared thermometer, the three-stand universal mills and the box type heater.

The initial workpiece for the rail universal rolling is a $18 \mathrm{~kg} / \mathrm{m}$ light rail which length is $6 \mathrm{~m}$. This light rail is divided into 20 pieces and the length of every pieces is $300 \mathrm{~mm}$ long. For biting into the gap easily, the head of workpiece is cut as same as the profile of FEM model.

A part of rolled pieces are shown as Fig. 18.

For obtaining the value of forward slip coefficient, some pits are chiseled on the surface of the horizontal roll and vertical roll with the same distance, and some humps on the surface of workpiece can be obtained after the workpiece is rolled in the universal mill. As can be seen in Figs. 19(a), 19(b) and 19(c), the forward slip coefficient can be calculated by measuring the distance between two adjacent hump.

\section{Results and Discussions}

The field data, the Rigid-Plastic FEM simulation results and the theoretical model results of forward slip coefficient

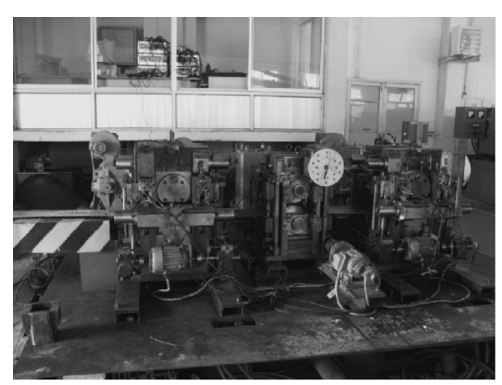

(a) The three-stand universal mills

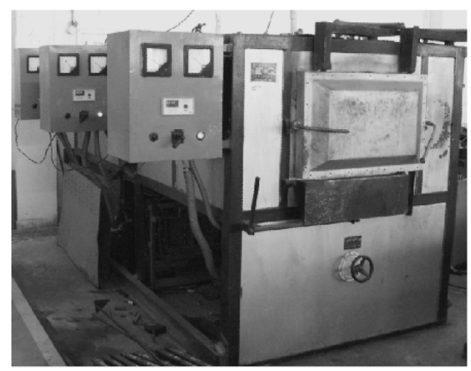

(b) The box type heater

Fig. 17. The main equipments for rail universal rolling. in $60 \mathrm{~kg} / \mathrm{m}$ heavy rail universal rolling is listed in Table 6, and the field data the experimental results, the Rigid-Plastic FEM simulation results and the theoretical model results of forward slip coefficient in light rail universal rolling experiments is listed in Table 7.

As can be seen in Table 6 and Table 7, the forward slip coefficient of the web of rail is always less than 1 in rail universal rolling. That's to say, the deformation zone of the web of rail is complete backward slip zone. On the contrary, the forward slip coefficient of the base and top of rail are always greater than 1 in rail universal rolling. Because the horizontal roll is driving and the vertical roll is driven, the metal flow of the web of rail will be restricted by the base and top of rail and the outgoing velocity of the web of rail is less than the linear velocity of the horizontal roll. So the forward slip coefficient of the web of rail is always less than 1 . Since the corresponding vertical roll is actually driven by the base of rail or top of rail, the outgoing velocity of the base or top of rail is greater than the linear velocity of corresponding vertical roll.

\section{Conclusion}

In this paper, the method of force equilibrium has been employed to derive a series of equations for forward slip coefficient, which is applicable to different size of workpiece and different pass schedule.

(1) In general, the forward slip coefficient of the web is less than 1 in rail universal rolling. If the reduction of the base and top of rail is small enough in rail universal rolling, the forward slip coefficient of the web can be greater than 1.

(2) Whatever are the rolling conditions, the forward slip coefficient of the base and top of rail relative to the vertical roll is always greater than 1 .

(3) With the increment of web reduction and rotational speed of the horizontal roll, the forward slip coefficient of

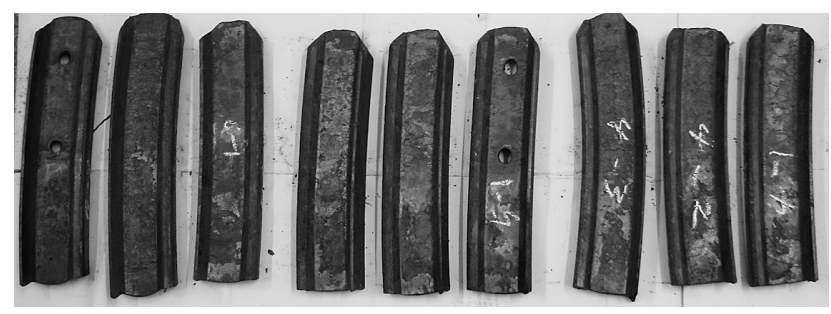

Fig. 18. A part of rolled piece.

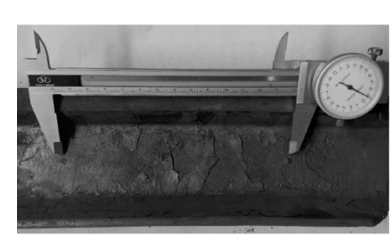

(a) The web of rail

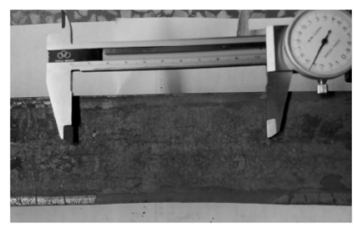

(b) The base of rail

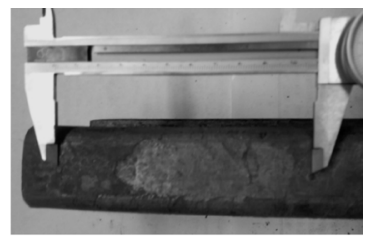

(c) The head of rail

Fig. 19. The measurement of the forward slip coefficient.

Table 6. The results comparison of forward slip coefficient in $60 \mathrm{~kg} / \mathrm{m}$ heavy rail universal rolling.

\begin{tabular}{c|c|c|c|c|c|c|c|c|c}
\hline \multirow{2}{*}{ Pass } & \multicolumn{3}{|c|}{$\delta_{w}$} & \multicolumn{3}{c|}{$\delta_{v b}$} & \multicolumn{3}{c}{$\delta_{v t}$} \\
\cline { 2 - 10 } & $\begin{array}{c}\text { Theoretical } \\
\text { model }\end{array}$ & FEM & Field data & $\begin{array}{c}\text { Theoretical } \\
\text { model }\end{array}$ & FEM & Field data & $\begin{array}{c}\text { Theoretical } \\
\text { model }\end{array}$ & FEM & Field data \\
\hline UR1 & 0.982 & 0.957 & 0.99 & 1.10 & 1.095 & 1.15 & 1.065 & 1.097 & 1.12 \\
\hline UR2 & 0.951 & 0.929 & 0.97 & 1.094 & 1.078 & 1.13 & 1.076 & 1.088 & 1.11 \\
\hline UR3 & 0.939 & 0.949 & 0.96 & 1.076 & 1.065 & 1.12 & 1.059 & 1.074 & 1.10 \\
\hline
\end{tabular}


Table 7. The results comparison of forward slip coefficient in the light rail universal rolling experiments.

\begin{tabular}{|c|c|c|c|c|c|c|c|c|c|}
\hline \multirow{2}{*}{$\begin{array}{c}\text { Workpiece } \\
\text { No. }\end{array}$} & \multicolumn{3}{|c|}{$\delta_{w}$} & \multicolumn{3}{|c|}{$\delta_{v b}$} & \multicolumn{3}{|c|}{$\delta_{v t}$} \\
\hline & $\begin{array}{c}\text { Experimental } \\
\text { data }\end{array}$ & FEM & $\begin{array}{c}\text { Theoretical } \\
\text { model }\end{array}$ & $\begin{array}{c}\text { Experimen } \\
\text { taldata }\end{array}$ & FEM & $\begin{array}{r}\text { Theoretica } \\
1 \text { model }\end{array}$ & $\begin{array}{c}\text { Experime } \\
\text { ntaldata }\end{array}$ & FEM & $\begin{array}{c}\text { Theoretical } \\
\text { model }\end{array}$ \\
\hline $1-1$ & 0.987 & \multirow{2}{*}{0.969} & \multirow{2}{*}{0.991} & 1.090 & \multirow{2}{*}{1.125} & \multirow{2}{*}{1.145} & 1.120 & \multirow{2}{*}{1.165} & \multirow{2}{*}{1.148} \\
\hline $1-2$ & 0.976 & & & 1.100 & & & 1.115 & & \\
\hline $2-1$ & 0.977 & \multirow{2}{*}{0.961} & \multirow{2}{*}{0.988} & 1.088 & \multirow{2}{*}{1.072} & \multirow{2}{*}{1.096} & 1.115 & \multirow{2}{*}{1.150} & \multirow{2}{*}{1.139} \\
\hline $2-2$ & 0.950 & & & 1.050 & & & 1.110 & & \\
\hline $3-1$ & 0.975 & \multirow{2}{*}{0.959} & \multirow{2}{*}{0.981} & 1.068 & \multirow{2}{*}{1.095} & \multirow{2}{*}{1.089} & 1.110 & \multirow{2}{*}{1.135} & \multirow{2}{*}{1.142} \\
\hline $3-2$ & 0.977 & & & 1.073 & & & 1.095 & & \\
\hline 4-1 & 0.975 & \multirow{2}{*}{0.960} & \multirow{2}{*}{0.984} & 1.050 & \multirow{2}{*}{1.085} & \multirow{2}{*}{1.075} & 1.090 & \multirow{2}{*}{1.126} & \multirow{2}{*}{1.112} \\
\hline $4-2$ & 0.967 & & & 1.065 & & & 1.085 & & \\
\hline $5-1$ & 0.962 & \multirow{2}{*}{0.954} & \multirow{2}{*}{0.976} & 1.060 & \multirow{2}{*}{1.076} & \multirow{2}{*}{1.085} & 1.090 & \multirow{2}{*}{1.105} & \multirow{2}{*}{1.116} \\
\hline $5-2$ & 0.957 & & & 1.063 & & & 1.080 & & \\
\hline $6-1$ & 0.958 & \multirow{2}{*}{0.947} & \multirow{2}{*}{0.971} & 1.050 & \multirow{2}{*}{1.070} & & 1.085 & & \\
\hline $6-2$ & 0.960 & & & 1.081 & & & 1.079 & & \\
\hline
\end{tabular}

the web of rail increases. With the reduction's increment of the base and top of rail, the forward slip coefficient of the web of rail decreases. Moreover, the rotational speed of the horizontal roll influences the forward slip coefficient more than else factors.

(4) The theoretical results and simulation results are in agreement with the experimental data basically. So, this theoretical model can be applied in rail rolling.

\section{Nomenclature}

$\alpha_{h}: \quad$ Bite angle of the horizontal roll

$\alpha_{v b}$ : Bite angle of the vertical roll for rolling the base of rail

$\alpha_{v t}$ : Bite angle of the vertical roll for rolling the top of rail

$V_{h}$ : Linear velocity of the horizontal roll

$V_{v t}$ : Linear velocity of the vertical roll for rolling the top of rail

$V_{v b}$ : Linear velocity of the vertical roll for rolling the base of rail

$H_{w 0}$ : The height of the web of rail at the entrance section

$H_{w 1}$ : The height of the web of rail at the exit section

$H_{b 0}$ : The height of the web of rail at the entrance section

$H_{b 1}$ : The height of the base of rail at the exit section

$W_{b 0}$ : The width of the base of rail at the entrance section

$W_{b 1}$ : The width of the base of rail at the exit section

$R_{h}$ : The radius of horizontal roll

$R_{v b}$ : The radius of vertical roll for rolling the base of rail

$\frac{G_{v t}}{}$ : The equivalent gap of the vertical roll rolling the top of rail

$G_{v t}$ : The gap of the vertical roll rolling the top of rail

$D_{v b}$ : The diameter of vertical roll for rolling the base of rail

$\overline{D_{v t}}$ : The equivalent diameter of vertical roll for rolling the base of rail

$\overline{P_{h}}$ : Mean unit pressure acting on the web from the horizontal roll

$\overline{P_{v t}}$ : Mean unit pressure acting on the top of rail from the vertical roll

$\overline{P_{v b}}$ : Mean unit pressure acting on the rail base from the vertical roll

$\overline{P_{h t}}$ : Mean unit pressure acting on the top of rail from the flank of horizontal roll

$\overline{P_{h b}}$ : Mean unit pressure acting on the rail base from the flank of horizontal roll

$\mu_{h w}$ : Friction coefficient between the web and horizontal roll

$\mu_{h t}$ : Friction coefficient between the top of rail and the flank of horizontal roll $\mu_{h b}$ : Friction coefficient between the rail base and the flank of horizontal roll

$\mu_{v t}$ : Friction coefficient between the top of rail and vertical roll

$\mu_{v b}$ : Friction coefficient between the top of rail and vertical roll

$\mu_{0 b}$ : The equivalent friction coefficient of the bearing of the vertical roll for rolling the base of rail

$R_{0 b}$ : The equivalent radius of the bearing of vertical roll for rolling the base of rail.

$\mu_{0 t}$ : The equivalent friction coefficient of the bearing of the vertical roll for rolling the top of rail

$R_{0 t}$ : The equivalent radius of the bearing of vertical roll for rolling the top of rail.

\section{REFERENCES}

1) S. Zhao: Xian Met Architecture Inst., 12 (1982), 68.

2) Z. Wang: Dissertation of the Master Degree in Engineering, Yanshan University, (1984).

3) X. Jin: Dissertation of the Master Degree in Engineering, Yanshan University, (1990).

4) K. Ikuta, K. Aoyagi and T. Kawanami: ISIJ Int., 35 (1995), 1089.

5) W. Zhang, C. Zhu and G. E. O.Widera: J. Mater. Process. Technol., 54 (1995), 114

6) W. Zhang, C. Zhu and G. E. O. Widera: J. Mater. Process. Technol., 56 (1996), 820 .

7) W. Zhang, Q. Zhou, C. Zhu et al.: J. Mater. Process. Technol., 94 (1999), 123.

8) W. Zhang, Q. Zhou, Y. Li et al.: J. Mater. Process. Technol., 101 (2000), 115.

9) T. Iguchi, H. Hayashi and I. Yarita: Proc. 1st Int. Conf. on Modeling of Metal Rolling Processes, The Institute of Materials, London, (1993), 707.

10) M. Kiuchi and J. Yanagimoto: ISIJ Int., 30 (1990), 142.

11) K. Komori and K. Koumura: J. Mater. Process. Technol., 105 (2000), 24.

12) Y. Lee and S. Choi: ISIJ Int., 40 (2000), 624.

13) Y. Lee, H. J. Kim, S. M.: J. Mater. Process. Technol., 114 (2001), 129.

14) Y. Lee: ISIJ Int., 41 (2001), 1414

15) Y. Dong, W. Zhang and J. Song: ISIJ Int., 46 (2006), 1458.

16) G. Bai: The Pass Design of Strctural Sections, Metallurgical Industry Press, Beijing, (1995), 28.

17) Y. Xue and C. Gao: The Press Working of Special Steel, Metallurgical Industry Press, Beijing, (2000), 86.

18) J. Shang: Dissertation of the Master Degree in Engineering, University of Science and Technology Beijing, (2001).

19) J. Zhou and K. Guan: The Metal's Resistant to the Plastic Deformation, Metallurgical Industry Press, Beijing, (1989), 221. 